Discussion Paper No. 06-026

\title{
Private Job Placement Services - A Microeconometric Evaluation for Germany
}

Henrik Winterhager

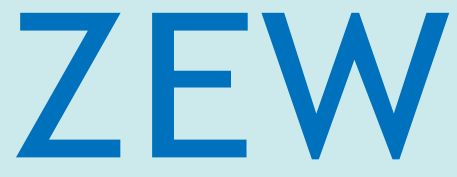

Zentrum für Europäische Wirtschaftsforschung $\mathrm{GmbH}$ Centre for European Economic Research 
Discussion Paper No. 06-026

\title{
Private Job Placement Services - A Microeconometric Evaluation for Germany
}

\author{
Henrik Winterhager
}

Download this ZEW Discussion Paper from our ftp server:

ftp://ftp.zew.de/pub/zew-docs/dp/dp06026.pdf

Die Discussion Papers dienen einer möglichst schnellen Verbreitung von neueren Forschungsarbeiten des ZEW. Die Beiträge liegen in alleiniger Verantwortung der Autoren und stellen nicht notwendigerweise die Meinung des ZEW dar.

Discussion Papers are intended to make results of ZEW research promptly available to other economists in order to encourage discussion and suggestions for revisions. The authors are solely responsible for the contents which do not necessarily represent the opinion of the ZEW. 


\section{Non-technical summary}

Contracting out of placement services was introduced in Germany in 2002 to make placement services for unemployed individuals more effective and efficient and thereby reduce frictional unemployment. In principle, a system of private providers can lead to better quality and cost efficiency in placement services by allowing flexibility and introducing competition as well as success based compensation. The government remains the financier and has management and policy control over the type and quality of services to be provided. On the basis of contracts between public job centers and private providers, public caseworkers choose unemployed individuals to send to the private providers who, in turn, try to match the individuals with suitable employment. The remuneration paid to the providers depends mainly on their success rate in placement.

The empirical part of this paper analyzes the use of this instrument and its effectiveness from the perspective of the unemployed individuals assigned to a private provider for the complete placement activities, i.e. all the activities necessary to place him in a job. The selectivity of the assignments is taken into account in the microeconometric evaluation study that uses propensity score matching to solve the evaluation problem. The plausibility of the identifying conditional independence assumption is discussed. The highly informative administrative data provided by the Federal Employment Agency minimizes selection on unobservables, so the matched control group is a reliable proxy for the unobserved counterfactual. It is argued that unobserved heterogeneity is small enough to get a negligible bias.

The estimated effect of the assignment to private providers on the probability of employment is small and negative: 2.3 to 2.6 percentage points after 2 months. The positive effects on the probability of unemployment are even bigger, up to 7 percentage points. The effects are only temporary, vanishing after some months. On average, the private providers were less successful in placing their clients than the public employment offices at the beginning of 2004. This might be explained by deficits in the contract management. The design of the tender allowed providers who combined low quality with a low price to be awarded the contracts. Information mechanisms did not seem to be effective and the incentive effect of the payment was rather small. The results show a positive relationship between the amount of the premium and the estimated treatment effect. However, establishing a causal relationship is problematic because the amount of the payment results from a tender and hence is endogenous. A valid instrumental variable for the premium to control this endogeneity is not available for 2004.

Based on the results of this microeconometric evaluation the conclusion is that there should be modifications in the contracting out of placement services relative to the design of 2004 . Given the theoretical considerations and the empirical evidence, the design of the tender process and the compensation scheme are starting points for these changes. 


\title{
Private Job Placement Services - \\ A Microeconometric Evaluation for Germany
}

\author{
Henrik Winterhager ${ }^{\#}$ \\ Zentrum für Europäische Wirtschaftsforschung GmbH (ZEW) \\ L 7, 1, D-68161 Mannheim
}

\begin{abstract}
:
In recent years, coinciding with the discussion led in many OECD countries, Germany has started to contract out placement services for the unemployed to private agencies. Whereas in the Netherlands and Australia the whole system of employment services was reorganized at once, making an econometric evaluation difficult, only a small part of services has been contracted out so far in Germany. In this paper a microeconometric evaluation of this system using propensity score matching is presented. The effects on the employment probabilities of the unemployed are small and negative so far. A theoretical analysis suggests that this might be explained by deficits in the contract management.
\end{abstract}

Keywords: Job Placement, Contracting Out, Active Labor Market Policy, Matching JEL Classification: J 68, H 25

Acknowledgements: I am grateful to Melanie Arntz, Anja Heinze, Anja Kuckulenz, Thomas Kruppe, Michael Lechner, Werner Sörgel, Alexander Spermann and Thomas Zwick for very helpful comments. My special thanks go to Friedhelm Pfeiffer for his precious advice and many hours of constructive discussion. This project has been financed by the Institute for Employment Research of the German Federal Employment Agency (IAB). I thank the IAB for access to the data. The usual disclaimer applies.

\footnotetext{
\# Corresponding author: Henrik Winterhager, Centre for European Economic Research (ZEW), PO Box 103443, D-68034 Mannheim, Tel.: +49-621-1235-280; fax: +49-621-1235-225. E-Mail: winterhager@zew.de
} 


\section{Introduction}

The contracting out of placement services for unemployed individuals is a subject of discussion in many OECD countries today. The objectives of such a step are an increase in the effectiveness of services, i.e. faster placement of clients, and cost savings. This is meant to be achieved by introducing competition into the industry and installing performance based competition. Furthermore, private providers are more flexible than the agencies of the former public monopolist, the Federal Employment Agency (Bundesagentur für Arbeit). Theoretical considerations suggest that whether contracting out actually raises the effectiveness of placement services depends crucially on the contract management. The coexistence of public placement services and the selection into the program must also be kept in mind.

Up to now, only two countries have contracted out their placement services completely: Australia (Dockery and Stromback 2001) and the Netherlands (OECD, 2003, Struyven and Steurs, 2004). If the whole system is changed as in these two countries, it is difficult to evaluate the consequences of such a reform. A before-after estimator has the disadvantage that it is biased by changes in the overall state of the economy. There are no untreated individuals in the same country that can be used to build a control group. A control group in another country is problematic in that all other country-specific developments have to be filtered out. In contrast to this, if only a part of the placement services is contracted out, as in Germany, it is possible to examine the effectiveness of this tool by means of a microeconometric evaluation. Even though the estimated treatment effect is different from that which we would expect in the case of a complete system change, this is a useful piece of additional insight.

Job placement in Germany was a public monopoly until 1994. Regulation was partly loosened then but still remained strict in comparison with more deregulated markets in Great Britain or the Netherlands (Konle-Seidl and Walwei, 2002). With rising unemployment figures in Germany, the effectiveness and efficiency of the Federal Employment Agency was increasingly questioned in the late nineties. Because a large share of its some 90.000 employees worked in administrative jobs and only a small proportion directly as caseworkers for the unemployed, the ratio of caseworkers to unemployed individuals was 
about 1:600-800 in 2002 (Hartz-Kommission, 2002). ${ }^{1}$ One instrument to draw on private placement agencies for the placement of unemployed persons is the job placement voucher, introduced in 2002. The voucher seems to have positive direct effects on the users (see Pfeiffer and Winterhager, 2006a, Winterhager et al. 2006). Also in 2002, the government started to contract out placement services to private providers. From January to September 2004, 8 percent of the people who registered as unemployed were assigned to a private provider for complete placement activities, i.e. all the activities necessary to place him in a job.

This paper presents the results of a microeconometric evaluation of assignments of unemployed individuals to private providers in Germany in the first quarter of 2004. ${ }^{2}$ The analysis provides new insight into how effective it is to contract out placement services. Theoretical discussions identify the key factors for successful contracting out: careful selection of the private providers and the implementation of governance mechanisms to avoid moral hazard. A theoretical analysis can thus identify the potential for improvements, but it cannot tell whether a given design of the contracting scheme is actually more effective compared to a pure public provision of the service. The only possibility is to look at the data. With a rich administrative data set provided by the Federal Employment Agency a matching approach is implemented to estimate the average effect of treatment on the treated. Treatment is defined as approaching a private agency which tries to place the person assigned to them. The treatment effects are estimated by nearest neighbor propensity score matching with replacement.

The most important results of the paper are the following: The estimated effect of assignment to a private provider on the probability of employment is small and negative. The employment probability of an unemployed individual who is assigned is reduced by 2.3 to 2.6 percentage points after 2 months. The positive effects on the probability of unemployment are even bigger, up to 7 percentage points. The effects vanish after some months which is in line with the assignment duration of three months. Overall, the private

1 However, it has to be kept in mind that these figures were produced by the administration itself and might be politically motivated.

2 The evaluation study was financed by the Institute for Employment Research of the German Federal Employment Agency; IAB-Projekt 544a „Begleitforschung zur Vermittlung - Implementation und Evaluierung von Beauftragungen nach § 37(a) SGB III, Vermittlungsgutscheinen und PSA“, also see Kruppe (2006). 
providers were not more successful in placing their clients than the public employment offices in the beginning of 2004. Furthermore, there seems to be a positive relationship between the amount of the success-based payment and the estimated treatment effect, hinting at the crucial role of the incentive mechanism.

The paper is structured as follows. Section 2 is devoted to a detailed description of the system of contracting out in Germany as regulated in $\S 37$ SGB III (code of social law). Following new institutional economics, marketability as a precondition for contracting out is discussed as well as the design of the contract management. Section 3 describes the administrative data set provided by the Federal Employment Agency as well as the samples used for the analysis; Section 4 presents descriptive statistics for the instrument. The methodology and the identifying assumptions of the matching approach are discussed in Section 5. The average treatment effect on the treated is estimated by propensity score matching. Section 6 reports the empirical results and Section 7 concludes.

\section{Institutional details and theoretical considerations}

\subsection{Institutional framework for contracting out}

As in many other European countries, job placement used to be a public monopoly in Germany, until the early 1990s. It was only in 1994 that the government permitted private job placement. But regulation still remained strict in comparison with much more deregulated markets in Great Britain and the Netherlands (Buttler and Walwei 1995, KonleSeidl and Walwei 2002).

At the beginning of 2002 the government introduced outsourcing of placement tasks in $\S 37$ a SGB III (nowadays $\S 37$ ). ${ }^{3}$ In 2002, the selection of external providers was realized on a discretionary basis in local public employment offices (Konle-Seidl, 2005). In 2003, the implementation of $\S 37$ SGB III was modified so that the placement tasks were tendered on a central level and the payments more incentive-oriented. Due to these changes, real contracting out of placement tasks was implemented in 2003. Further modifications to the implementation were carried out in the following years. Since the study concentrates on 2004 for reasons of data availability, the institutional setup for that year will be described in detail now.

3 To avoid confusion, we will talk of $\S 37$ from now on. 
$\S 37$ SGB III regulates the contracting out of placement tasks to private providers. There are three types of tasks contracted out:

- the complete placement activities for a jobseeker or a person looking for basic job training; these are all the activities which aim at placing the person within a job or job training

- parts of the placement activities for a jobseeker or a person looking for basic job training (e.g. profiling)

- $\quad$ acquisition of vacancies for undetermined jobseekers or persons looking for basic job training.

Since the objective is to investigate the effects on individual employment probabilities, the acquisition of vacancies is not considered. The second type of task (e.g. profiling, case management) is also omitted here because it was cut back as early as in 2004 and was completely dropped at the beginning of 2006. The paper therefore concentrates on the first type, which is directly aimed at integrating an individual into employment. Concerning the target group, the focus of the paper is on unemployed jobseekers.

After a tender (described below) the local public employment office makes a contract with a private provider. In this contract the public employment office commits to assigning a certain number of jobseekers ${ }^{4}$ to the provider during a certain period (contract period). The provider has to accomplish exactly one of the tasks mentioned above for these jobseekers. He is given a certain time to do this for every single jobseeker (assignment period). In the case of complete placement activities, the assignment period is usually 3 months but can be prolonged if the integration of a jobseeker seems difficult.

The compensation of the provider is incentive oriented. In case of successful integration of the jobseeker into employment during the assignment period ${ }^{5}$ a premium is paid, the absolute amount of which is determined in the tender. For employment that lasts for more than six months, a bonus will be paid after these six months (the same amount as the premium). These rules are the same for all jobseekers. In addition, for jobseekers who have been unemployed for more than 6 months, a lump sum is paid after the jobseeker has called on the provider for the first time. The amount depends on the duration of previous

\footnotetext{
4 There are usually certain types of job seekers defined, e.g. a certain age group or unemployment duration.
} 
unemployment: 15 percent of the premium in case of unemployment that lasted between 6 and 12 months and 25 percent for unemployment for more than a year. The private provider has to give a formal account of its efforts for each single unemployed person in order to receive the payments.

Jobseekers who have been unemployed for more than six months have the right to be assigned to a private provider. But caseworkers in the public employment offices can also assign the short term unemployed to a provider. If the caseworker wants to assign a jobseeker to a provider, the jobseeker can refuse if he can provide a reasonable justification such as, e.g., a case for nursing care in the family which prevents him from entering the assignment. If the jobseeker refuses the assignment without justification, this should lead to revision of his benefit entitlement.

As mentioned above, contracts are awarded to private providers after a central tender. All providers with the necessary qualifications are taken into consideration. The provider who offers the lowest premium is awarded the contract. The bonus and, where applicable, the lump sum are determined by the premium in the described way.

In 2004, in addition to the contracts described so far, some contracts awarded in 2003 were still valid and had to be fulfilled by the public employment offices. Part of these contracts also comprised the complete placement activities. The main difference from the new contracts was that the compensation structure could be defined by the local offices and thus was more diverse than in the standardized contracts of 2004. The assignments governed by these contracts comprising complete placement activities are included in the microeconometric evaluation. The treatment is very similar and more variation is added to the compensation structure which can be exploited in the econometric analysis. A check is also carried out to establish whether the treatment effect of these old contracts differs from the one of the new contracts.

\subsection{Theoretical background}

When analyzing placement services for unemployed persons, first one has to ask if a government intervention can be justified at all. Is there a market failure? Four problems can be identified. First, there are information asymmetries between the unemployed, possible employers and placement agencies. Second, placement services can have important

\footnotetext{
5 It must not be a temporary employment contract with a duration of less than three months.
} 
externalities with respect to the unemployment insurance system. Third, there might be credit restrictions for unemployed persons who cannot pay for placement services themselves. Fourth, more recent literature suggests that in the presence of time inconsistent preferences (hyperbolic discounting) policies for unemployed workers can represent a Pareto improvement (DellaVigna and Paserman, 2005). These matters cannot be discussed here in detail, but usually authors come to the conclusion that some kind of government intervention is necessary (e.g. Kretschmer, 2005, p. 129ff.; Heidinger, 2002, p. 92ff.). Next, one should ask whether it is more effective and efficient if the government provides this service itself or if it contracts it out to private providers. ${ }^{6}$

The minimum requirement for contracting out of placement services is fulfilled, because the service is marketable (see Bruttel, 2005):

- The investment specificity (see Williamson, 1985) of the service is not too high. Countries like Australia and the Netherlands have shown that know-how in placement services for less qualified unemployed individuals can be built up in a rather short time. Even though until recently only 2 percent of job matches in Germany were arranged by private agencies (Kettner and Spitznagel 2005), there are many private firms, e.g. from the training sector, that can enter the market. So structures from which private placement can develop exist and it is possible to make the market contestable (see Baumol, 1982; Martin, 1993).

- Hart et al. (1997) argue that public services should only be delivered by private providers if the contractual obligations can be laid down in sufficiently exact terms and if compliance can be ensured. In placement services for the unemployed, it is particularly important that the quality of services is assured for all individuals. In principle, this is possible.

Whether contracting out increases the effectiveness of the service will depend on the contract management. The contract management involves the issues of selecting the private providers and implementing effective governance mechanisms. The selection of the private providers is important because screening can prevent adverse selection. For $\S 37$ the selection is conducted by means of centralized tenders as described above. In 2004, there was only a minimum qualification level required for the private providers to be able to bid in

6 The following theoretical approaches are sometimes summarized in the literature under the label new 
the tender. Apart from this minimum requirement, the quality of the provider did not play a role. The contract was awarded on the basis of the lowest price offered. One would not expect such a selection process to be sufficient to avoid adverse selection. To the contrary, those providers that combine a low price with low quality will be awarded the contracts. This seems to be confirmed by a survey of experts in 50 local public employment offices (sinus, 2006). 60 percent of them reported that in the (centralized) tender private contracts were awarded to providers whom they would not have considered appropriate because of a lack of qualification.

The second issue of contract management is the implementation of governance mechanisms to avoid moral hazard. This is the subject of the principal agent theory. In a situation of information asymmetries and incomplete contracts, moral hazard means the increased risk of problematical (immoral) behavior, and thus a negative outcome, because the agent who causes the problem does not suffer the full (or any) consequences. There are three governance mechanisms to reduce moral hazard: incentive mechanisms, information mechanisms and control mechanisms (Bruttel, 2005). Information mechanisms include performance measurement and are aimed at reducing the information asymmetry between principal and agent. Control mechanisms imply that the provision of service is regulated, which leads to a loss of flexibility. $\S 37$ combines an incentive mechanism (performance based compensation) and an information mechanism (formal report of the provider on the efforts for each assigned individual). However, due to the high work load in the public employment agencies, the reports were usually not checked very carefully in 2004. The performance of the private providers did not play a role in later tenders.

The incentive mechanism depends on the amount of the premium in case of placement and the bonus after six months of employment. Yet this amount was not fixed but instead emerged in the tender. As described above, the design of the tender was such that low premiums could be expected. And this was actually what happened, as will be shown in the next section. These rather low premiums meant the incentives for the providers to invest efforts into placement activities for the persons assigned to them were small.

Even though some deficits in the contract management for the contracting out regulated by $\S$ 37 in Germany in 2004 have been identified, it is not clear from a theoretical perspective if the assignment of unemployed individuals has negative individual effects. This is because it

institutional economics. For an introduction see Furubotn and Richter (1998). 
is possible that the public provision of services is less effective. This has to be tested in the empirical part.

\section{Data}

The data used for the empirical analysis originate from the Federal Employment Agency. It was not until January 2004 that an IT system was installed to systematically control the use of contracting out according to $\S 37$. For this reason earlier use of the instrument cannot be evaluated. The system stores each jobseeker who is assigned to a private provider. In addition the start and end dates of the assignment are registered, as well as which type of task has to be accomplished by the provider, the structure and the amount of the determined compensation, and when the jobseeker called on the provider for the first time, if at all. Data until September 2004 are available for this study. The data can be linked with other individual data from the Federal Employment Agency described below (see also Hujer et al., 2004, Lechner et al., 2001).

From the jobseeker's data base (BewA), which contains spell data for all the unemployed persons registered with a public employment agency, a lot of information on the individuals can be drawn: socio-economic characteristics, qualifications, recent labor market history and information about their desired job. To get more information on the long term labor market history of each individual, the newly created integrated employment biographies (IEB) data base is used (Hummel et al., 2005). This data set contains spell data from four different sources: the above-mentioned BewA, the data bases on regular employment $(\mathrm{BeH})$, on benefits paid by the Federal Employment Agency to the unemployed (LeH) and on labor market programs the individuals participate in (MTG). The IEB was created to evaluate the labor market policy reforms introduced in Germany since 2004 (the so-called Hartz reforms). As argued below, the exact data on the employment history are very useful to reduce unobserved heterogeneity between the individuals. The IEB is also needed to measure the integration into regular employment after the assignment. ${ }^{7}$ In general, the data can only be used after careful validations and corrections (described in Heinze et al., 2005).

\footnotetext{
Actually the standard IEB data had to be supplemented by employment data for 2004. At the time when these data were supplied for this study, their degree of completeness was only 80 to 90 percent. This is because employment data have to be reported by employers to the department of social security. As there is no reason to assume that the incompleteness of the data is related to the treatment, the employment shares
} 
The time frame for the econometric analysis is narrow. As stated above, no reliable data existed on the use of the instrument before 2004. Furthermore, data on regular employment were only available until the end of 2004. This leads to the following strategy: a sample of the assignments in the first quarter of 2004 is used, so that the observation of nine months after the assignment date is possible. For the premium to be paid under the standardized contracts, employment must start during the assignment period of three months. The bonus is paid after six months of employment, so this event is also included in the observation period for the sample. After all the data validations, 43,526 assignments can be used in this sample. ${ }^{8}$

\section{Descriptive statistics}

Figure 1 shows the development of the assignments from January to September 2004. The total number of assignments per month does not vary much. But this number also contains assignments due to contracts comprising only partial placement tasks. This paper concentrates on the contracts described in Section 2, which comprise the complete placement activities. In Figure 1 it becomes evident that their number rises in the first months of the year, peaks at some 36,000 in April and falls back to about 26,000 in September. Altogether during these nine months about 250,000 jobseekers were assigned to a provider for complete placement activities, or 8 percent of the people who registered as unemployed during that time.

Thus the instrument reached only a limited number of unemployed persons in 2004. The small use of the instrument is also reflected in its costs: for the assignments for complete placement activities during the first half of 2004, Pfeiffer and Winterhager (2006b) calculate average costs of about $180 €$. This would lead to a sum of less than 70 million $€$ for 2004 , which is small in comparison to the 19.5 billion $€$ spent by the Federal Employment Agency on active labor market policies in that year.

For the analyses, treatment is defined as “approaching a private provider”. This answers the question if the private providers work more effective under the given setting. This is slightly different from the treatment "being assigned to a private provider", because some of the unemployed who were assigned did not approach the provider. But as the share is less than 5

for participants and non-participants and thus the treatment effect will be underestimated by 10 to 20 percent. 
per cent, the difference between the two corresponding treatment effects is small. The date of the treatment is chosen as the first approach to the provider. Anticipatory effects due to the fact that the assignment takes place before the first approach will be negligible because the average time between the two dates is less than a week.

Figure 1: Number of assignments (§ 37 SGB III) from January to September 2005; all assignments, assignments for complete placement activities

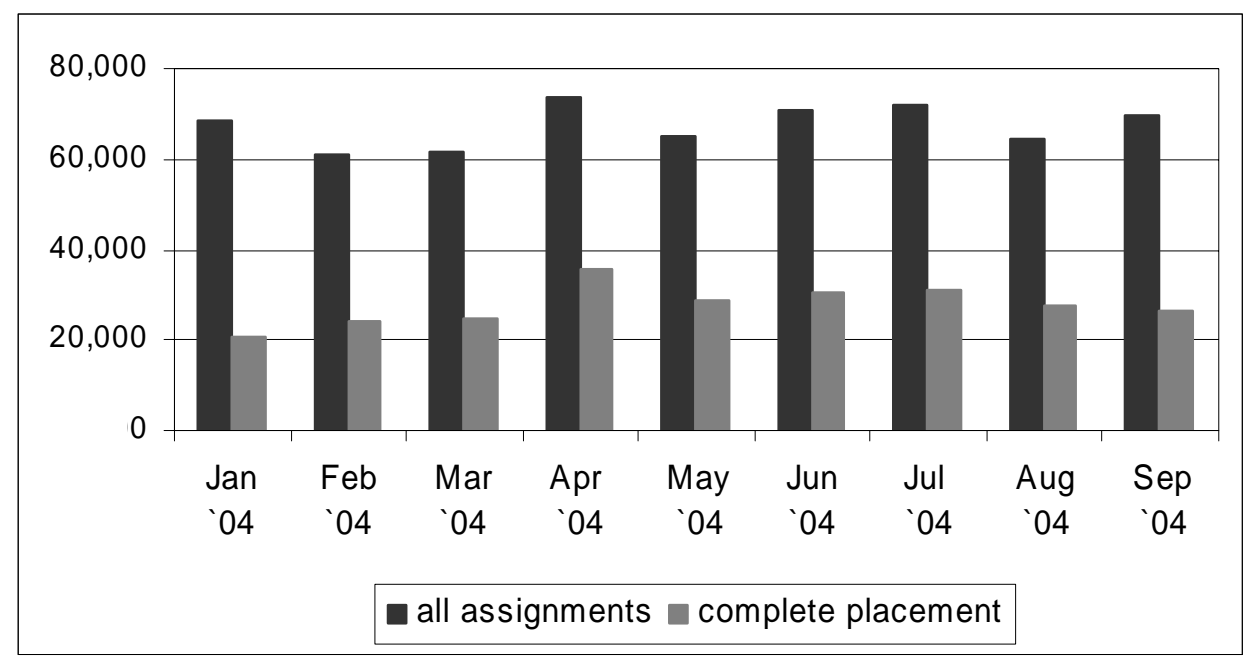

Source: own calculations using data from the Federal Employment Office, see text

In a dynamic setting, it is necessary to consider which non-participants are included in the analysis. One possibility would be to include those persons who are never assigned during their unemployment spell. But Sianesi (2004) argues that within the Swedish system an unemployed person will join a program at some time, provided that the individual remains unemployed long enough. The reason why an unemployed individual is not observed to participate in the program is that the person has already found a job or the time horizon of the analysis is too short. Consequently, she defines non-participants as those persons who are not treated during a given time interval, but who may get the treatment later. This means that the estimated treatment effect compares "treatment today" to "later treatment or no treatment”. This approach is followed here because of the short time horizon of the analysis. The fact that only a small part of the unemployed individuals is assigned means that the difference between the two definitions is negligible. 
Excluded from the control group are participants in other active labor market programs at the reference date (like retraining or job creation schemes) and recipients of job placement vouchers. ${ }^{9}$ This means that we measure the effect of the assignment versus using the placement services of the Federal Employment Agency without participating in any labor market program. Otherwise our estimated effect would be influenced by the effect of other programs. However, individuals who participated in such programs later on are not excluded. Thus, we implicitly view these policies as one possible consequence of being or not being assigned. ${ }^{10}$

The characteristics of the assigned unemployed and the others are compared in Table 1. Analyses were conducted separately for eastern and western Germany, as the two regions still feature very different labor markets. It becomes evident that the caseworkers assign the unemployed in a selective way. The participants are six to seven years younger on average. Foreigners and married persons are underrepresented and, in eastern Germany, females. Especially in western Germany, the share of persons without complete vocational training is smaller among the assigned unemployed. Finally, their previous unemployment duration is more than four months shorter in western Germany and more than five months shorter in eastern Germany. Altogether, looking at these observable characteristics of both groups, one would conclude that the caseworkers tend to send individuals with better employment opportunities to the private providers.

There is considerable variation between the labor market districts regarding the use of private providers. The share of individuals assigned in the first quarter of 2004 lies between 0 and 9.4 percent. Only a small part of this variation can be explained by the local labor market conditions like unemployment rate or number of unemployed per caseworker. Most of the variation seems to be caused by the different attitudes towards the instrument in the local employment agencies, as reported in a survey with local experts (see sinus 2006).

9 This instrument allows individuals unemployed for more than three months to make use of the services of a private placement agency; the private agency is rewarded by the public employment office in case of successful placement. See Pfeiffer and Winterhager (2006b) and Winterhager et al. (2006) for evaluation analyses on the job placement voucher.

10 This approach is also followed in Gerfin and Lechner (2002) and Sianesi (2004). 
Table 1: Comparison of unemployed assigned to a private provider from January to March 2004 and others, selected attributes

\begin{tabular}{|c|c|c|c|c|}
\hline & \multicolumn{2}{|c|}{ East } & \multicolumn{2}{|c|}{ West } \\
\hline & assigned & not assigned & assigned & not assigned \\
\hline Number & 16,126 & 939,501 & 27,400 & $2,261,562$ \\
\hline \multicolumn{5}{|l|}{ general socio-demographic attributes } \\
\hline age (years) & 34.3 & 41.4 & 34.3 & 40.3 \\
\hline foreign & $0.57 \%$ & $1.47 \%$ & $14.51 \%$ & $16.25 \%$ \\
\hline female & $41.97 \%$ & $47.84 \%$ & $39.63 \%$ & $40.39 \%$ \\
\hline married & $32.63 \%$ & $49.65 \%$ & $36.57 \%$ & $48.90 \%$ \\
\hline health problems (binary) & $18.50 \%$ & $21.77 \%$ & $16.26 \%$ & $25.11 \%$ \\
\hline \multicolumn{5}{|l|}{ schooling } \\
\hline no school & $6.72 \%$ & $7.75 \%$ & $11.20 \%$ & $14.31 \%$ \\
\hline CSE & $29.98 \%$ & $30.37 \%$ & $49.18 \%$ & $52.71 \%$ \\
\hline O-levels & $57.46 \%$ & $55.05 \%$ & $26.73 \%$ & $20.19 \%$ \\
\hline adv. Technical college entrance & $1.65 \%$ & $1.69 \%$ & $5.92 \%$ & $4.63 \%$ \\
\hline A-levels & $4.20 \%$ & $5.13 \%$ & $6.97 \%$ & $8.16 \%$ \\
\hline \multicolumn{5}{|l|}{ vocational training } \\
\hline without complete training & $14.02 \%$ & $3.05 \%$ & $34.44 \%$ & $39.68 \%$ \\
\hline on-the-job vocational training & $69.00 \%$ & $7.22 \%$ & $53.36 \%$ & $47.72 \%$ \\
\hline classroom vocational training & $11.46 \%$ & $4.00 \%$ & $3.86 \%$ & $2.31 \%$ \\
\hline technical college & $2.87 \%$ & $4.05 \%$ & $4.50 \%$ & $4.53 \%$ \\
\hline university & $1.65 \%$ & $2.45 \%$ & $2.29 \%$ & $3.73 \%$ \\
\hline polytechnic & $0.99 \%$ & $14.26 \%$ & $1.55 \%$ & $2.04 \%$ \\
\hline \multicolumn{5}{|c|}{ qualification as seen by the caseworker (reference: no specialized knowledge) } \\
\hline unskilled employee & $30.63 \%$ & $37.55 \%$ & $42.29 \%$ & $49.36 \%$ \\
\hline skilled employee & $63.98 \%$ & $54.66 \%$ & $50.69 \%$ & $41.20 \%$ \\
\hline technical school level & $1.63 \%$ & $2.25 \%$ & $2.45 \%$ & $2.32 \%$ \\
\hline polytechnic level & $1.25 \%$ & $1.76 \%$ & $1.58 \%$ & $2.14 \%$ \\
\hline university level & $1.15 \%$ & $2.19 \%$ & $1.85 \%$ & $3.18 \%$ \\
\hline top executive & $0.01 \%$ & $0.02 \%$ & $0.04 \%$ & $0.05 \%$ \\
\hline others & $0.95 \%$ & $1.56 \%$ & $1.10 \%$ & $1.75 \%$ \\
\hline \multicolumn{5}{|l|}{ information about working history (short time) } \\
\hline $\begin{array}{l}\text { existing professional experience in } \\
\text { desired occupation }\end{array}$ & $69.71 \%$ & $82.49 \%$ & $78.77 \%$ & $85.14 \%$ \\
\hline daily wage of last employment $(€)$ & 19.3 & 19.7 & 25.1 & 25.4 \\
\hline $\begin{array}{l}\text { daily amount of unemployment benefits / } \\
\text { assistance (€) }\end{array}$ & 17.2 & 15.6 & 20.2 & 18.3 \\
\hline $\begin{array}{l}\text { duration of unemployment until issue } \\
\text { (days) }\end{array}$ & 324.3 & 484.4 & 253.6 & 388.0 \\
\hline
\end{tabular}

Source: own calculations using data from the Federal Employment Office, see text 
An important feature of the instrument is the premium for the private providers which constitutes the incentive mechanism of the contract management. As stated in Section 2, the premium is not generally fixed but depends on the tender. The amount of the premium in case of successful placement is then the same for all individuals assigned within a given contract. Table 2 reports the distribution of this premium on the individual level. In more than 90 percent of the cases it is below 800 Euro and in more than half of the cases below 400 Euro. It is higher in western Germany where the general price level is higher as well. Compared to the Australian system, these premiums are rather low (see Dockery and Stromback, 2001).

Table 2: premium in case of successful placement (1. payment)

\begin{tabular}{r|r|r|r|r}
\hline \hline & \multicolumn{2}{|c|}{ West } & \multicolumn{2}{c}{ East } \\
\cline { 2 - 5 } & \multicolumn{1}{|c|}{ Frequency } & Percent & Frequency & \multicolumn{1}{c}{ Percent } \\
\hline $0-200$ & 7,316 & $26.7 \%$ & 2,992 & $18,6 \%$ \\
$200-400$ & 7,864 & $28.7 \%$ & 5,393 & $33,4 \%$ \\
$400-800$ & 9,727 & $35.5 \%$ & 6,092 & $37,8 \%$ \\
$>800$ & 2,493 & $9.1 \%$ & 1,649 & $10,2 \%$ \\
\hline & 27,400 & $100.0 \%$ & 16,126 & $100.0 \%$ \\
\hline \hline
\end{tabular}

Source: own calculations using data from the Federal Employment Office, see text

The outcome that is of interest for this study is the labor market status in the 9 months after the treatment date. Three statuses are observed: "regular employment” without any subsidies from the employment office, "subsidized employment” which is partially or completely financed by the employment office ${ }^{11}$ and unemployment. Figure 2 presents the labor market status "regular employment” in the 12 months before and the nine months after the treatment date, both for assigned individuals and individuals not assigned. ${ }^{12}$ It becomes evident that in the year before the treatment a higher share of the assigned individuals is employed. This confirms that a positive selection seems to take place in the assignments. Because of this selectivity the higher value of the outcome after the treatment cannot be interpreted as the effect of the treatment. The next section will explain how this effect can be estimated.

\footnotetext{
11 Wage subsidies (Eingliederungszuschüsse) are used to support employment on the first labor market, job creation schemes (ABM) refer to the second labor market and have to be "additional”.

12 For the latter group a hypothetical treatment date has to be chosen, see section 5.3.
} 
Figure 2: Share of participants (assignment for complete placement activities) and non-participants in regular employment 12 months before and 9 months after the assignment date (assignments in the first quarter of 2004)

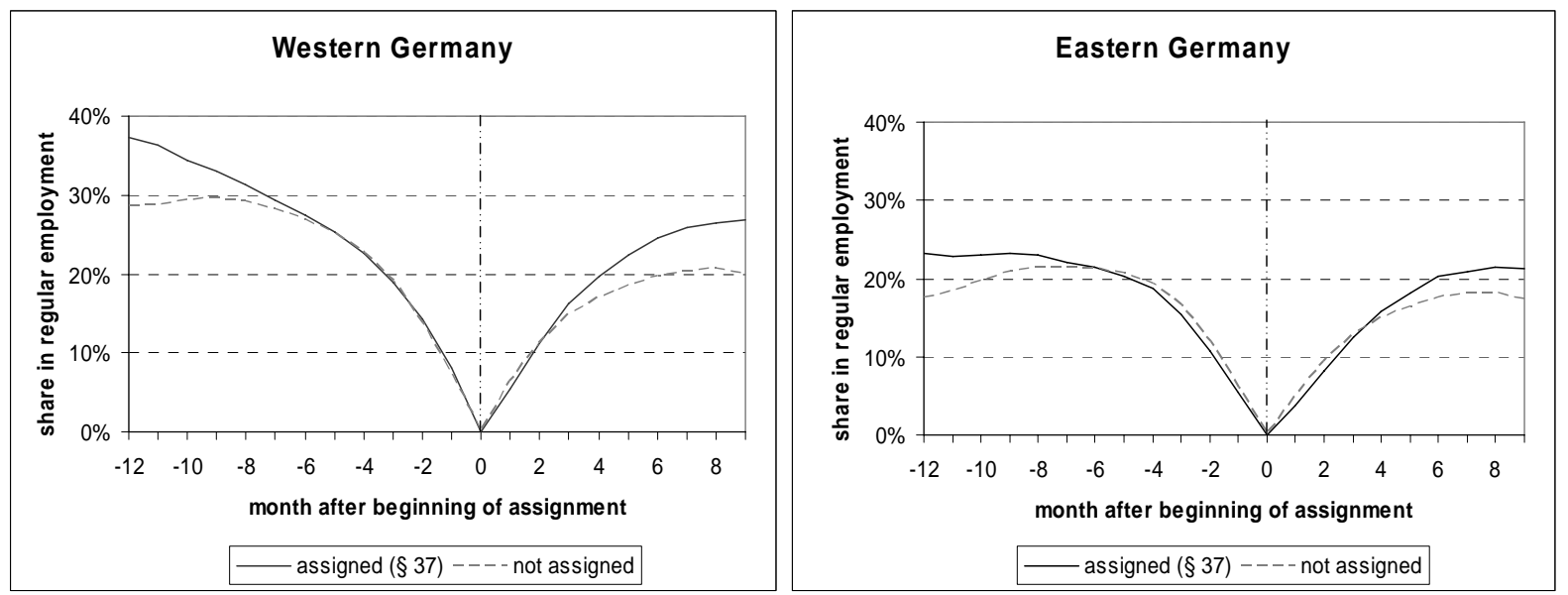

Source: own calculations using data from the Federal Employment Office, see text

\section{Evaluation approach}

The objective of this paper is to find the effect of approaching a private provider (treatment) on the individual probability for an unemployed person of entering into regular employment within the nine months following (outcome). This is called the evaluation problem. ${ }^{13}$ In Section 5.1, this evaluation problem will be formalized in the potential outcome framework and matching is presented as a possible solution. The identifying assumption of this approach will be discussed for the contracting out system in Section 5.2. Section 5.3 describes the implementation of the matching approach.

\subsection{Matching as a solution to the evaluation problem}

The microeconomic evaluation problem can be formalized in the potential outcome framework (see Heckman et al., 1999; Lechner und Pfeiffer, 2001). This representation requires the stable unit-treatment value assumption (SUTVA, see Rubin, 1980). For this assumption to hold, the contracting out system must not have indirect effects. One might expect the system to have substitution effects on other unemployed individuals: if private providers provide good services, employers will tend to recruit their clients instead of other unemployed persons. However, as stated above, only a small share of unemployed

13 For a survey on evaluation methods see Heckman et al. (1999), Blundell and Costa Dias (2002), Angrist and Krueger (1999). 
individuals are actually assigned to private providers, so indirect effects can be ignored and the potential outcome framework is applicable.

Let $D_{i}$ be a dummy variable that takes the value 1 if the unemployed person is assigned and 0 otherwise. Let $Y_{i}$ be the outcome variable which is 1 if the individual is in regular employment at a given date. More precisely, $\mathrm{Y}_{1 \mathrm{i}}$ is the outcome in case of assignment and $\mathrm{Y}_{0 \mathrm{i}}$ is the outcome in case of no assignment. We are actually interested in the treatment effect

$$
\Delta_{i}=Y_{1 i}-Y_{0 i} .
$$

It is never possible to observe $\mathrm{Y}_{1 \mathrm{i}}$ and $\mathrm{Y}_{0 \mathrm{i}}$ for the same individual at the same time, so $\Delta_{i}$ cannot be measured directly. This is the fundamental evaluation problem. To be able to estimate the treatment effect we have to use identifying assumptions. The parameter of interest in most evaluation studies is the average effect of treatment on the treated (ATT):

$$
A T T=E\left(Y_{1}-Y_{0} \mid D=1\right)=E\left(Y_{1} \mid D=1\right)-E\left(Y_{0} \mid D=1\right) .
$$

In our setting, this parameter would measure the average change in employment probability of the assigned persons that was actually caused by the assignment to the private provider. It is not an option to simply take $Y_{1}$ from the participants $(D=1)$ and $Y_{0}$ from the nonparticipants $(\mathrm{D}=0$ ) because the participants are not a random selection from the pool of unemployed individuals. Instead, the caseworker will select the individuals who are suited to be assigned and the unemployed individuals will or will not ask to be assigned. If this selection is based on criteria that are also correlated with the outcome, this will lead to a selection bias:

$$
E\left(Y_{0} \mid D=1\right) \neq E\left(Y_{0} \mid D=0\right)
$$

Instead, evaluation methods try to identify $E\left(Y_{0} \mid D=1\right)$ by using more data and certain identifying assumptions. A set of assumptions under which the ATT can be identified is the following:

$$
\begin{aligned}
& Y_{0} \perp D \mid X \\
& \operatorname{Pr}(D=1 \mid X)<1
\end{aligned}
$$

Assumption (4) is called the Conditional Independence Assumption (CIA). It states that once we control for a vector $\mathrm{X}$ of observable characteristics, the outcome in case of not being 
assigned to a private provider, $\mathrm{Y}_{0}$, does not depend on the assignment. This is a critical assumption, because all the characteristics which influence assignment and the outcome at the same time have to be observed. This assumption will be discussed in detail in Section 5.2. Assumption (5) is the common support condition. If it does not hold, i.e. $\operatorname{Pr}(D=1 \mid X)=1$, then there is no individual with characteristics $\mathrm{X}$ who is not assigned. In this case it is not possible to estimate the counterfactual $E\left(Y_{0} \mid D=1, X\right)$, even if assumption (4) holds.

Under assumptions (4) and (5) the counterfactual outcome of the participants (and thus the ATT) can in principle be estimated straightforwardly: for a participant with characteristics $\mathrm{X}=\mathrm{x}$ the average outcome of all the non-participants with $\mathrm{X}=\mathrm{x}$ is a consistent estimate of the counterfactual. But in practice, if the dimension of $\mathrm{X}$ is large and contains many continuous variables, there will be a large number of participants for whom no exact match exists (the “curse of dimensionality”, Heckman et al., 1997).

Rosenbaum and Rubin (1983) prove a result which is useful to reduce the dimensionality of the problem. They show that if the CIA holds, the following will hold as well:

$$
E\left(Y_{o} \mid D=1, p(X)\right)=E\left(Y_{o} \mid D=0, p(X)\right),
$$

where $\mathrm{p}(\mathrm{X})=\operatorname{Pr}(\mathrm{D}=1 \mid \mathrm{X})$, the probability of participation conditional on $\mathrm{X}$, is called the propensity score. It is thus not necessary to match on all the covariates, but it is sufficient to match on the propensity score. That makes it much easier to find an adequate match for the participants. As the propensity score is not observable, it has to be estimated by a parametric approach, such as probit. Dehejia and Wahba (2002) show that it is important to choose the specification of this estimation carefully in order to balance the covariates.

A matching estimator takes the form

$$
\hat{\alpha}=\frac{1}{N_{1}} \sum_{i=1}^{N_{1}}\left(Y_{1 i}-\sum_{j=1}^{N_{0}} w(i, j) Y_{0 j}\right),
$$

where $\hat{\alpha}$ is the estimated ATT, $\mathrm{N}_{1}$ and $\mathrm{N}_{0}$ are the numbers of participants and nonparticipants, and $w(i, j) \in[0,1]$ are the weights for the non-participants. Different matching estimators differ in these weights. In this paper single nearest neighbor matching with replacement will be used. That is, for each participant the non-participant who is closest with respect to the propensity score is chosen as control person, or formally 
$w_{N N}(i, j)=\left\{\begin{array}{l}1 \text { if } j=\underset{k \in\left\{1, \ldots, N_{0}\right\}}{\arg \min }\left|p_{i}-p_{k}\right| \\ 0 \text { else. }\end{array}\right.$

For the calculation of standard errors of the ATT, independent observations, fixed weights and homoskedasticity of the outcome variable within the treatment group and the control group are assumed (see Lechner, 2001). The variance is influenced by the fact that the propensity score is an estimated variable. In order to estimate the standard errors consistently, we would have to use bootstrapping (see Lechner, 2002), which is very timeconsuming for our sample. Lechner (2002) shows that in an application for Switzerland there is little difference between the bootstrapped variance and that which results from the following equation, which assumes that the variance is not influenced by the fact that the propensity score is an estimated variable:

$\operatorname{Var}(A T T)=\frac{1}{N_{1}} \operatorname{Var}\left(Y_{1} \mid D=1\right)+\frac{\sum_{j=1}^{N_{0}} \omega_{j}^{2}}{\left(N_{1}\right)^{2}} \operatorname{Var}\left(Y_{1} \mid D=0\right)$.

where $N_{1}$ is the number of treated individuals and $\omega_{j}$ is the weight of observation $\mathrm{j}$ in the matching. This equation will be used here to calculate the approximate standard errors of the ATT.

\subsection{Plausibility of the Matching Assumptions}

For the CIA to be justifiable, we would have to be able to observe all the criteria which influence both the individual probability of assignment and the outcome in the case of assignment. This assumption has to be discussed in relation to the available data set and the selection process. Less than 20 per cent of the unemployed who were assigned asked for the assignment on their own initiative. So the caseworker plays the central role in the selection process.

There are several motives for the caseworker to assign an unemployed individual to a private provider or not to do so. First, in the directives from the head office of the Federal Employment Agency, it is stated that the caseworker should assign an unemployed person if this is "reasonable and economic in the concrete individual case", i.e. if the unemployed person benefits from the assignment. Of course, this leaves the case worker with much scope for decision. However, it also appears that the caseworker should not assign an unemployed person who does not have a chance of finding a job anyway (at least not for the complete 
placement activities). Second, a caseworker might perceive the private providers as competition. For this reason he could assign unemployed individuals with low chances of getting a job so that the provider does not succeed in placing them. Third, if the caseworker wants to help the unemployed in finding jobs as fast as possible, his decision will depend on his personal opinion on the abilities of the private provider. Finally, if he wants to reduce his own workload, he will assign a large number of the unemployed.

This broad range of motives is reflected in a survey among the experts on contracting out from 50 local public employment agencies, that also asks which target group is primarily assigned to private providers (sinus, 2006). The result is that very different target groups are named by the agencies. Furthermore, 70 per cent of the agencies do not think that their workload is reduced through the assignments. Considering the possible motives and the survey results, there is apparently considerable heterogeneity in the selection process on the caseworker level. It is not generally the "good" or the "bad" unemployed who are assigned to the private providers. This is in line with the evidence on observable characteristics presented in Table 1 and reassuring for the discussion of the CIA.

The first two motives depend on the caseworker's assessment of the employment prospects of the individual in question. In the matching approach we must control for the variables related to this because they will be correlated with the outcome, i.e. employment. The caseworker's assessment of the employment prospects will depend on the observable characteristics of the unemployed individual, which can be found in the data:

- socio-demographic attributes such as gender, age, nationality, marital status, existence of infant children and health status

- the qualification of the unemployed person: school degree, professional training and actual qualification level seen by the caseworker; this last variable is an important indicator for the caseworker's assessment of the employment prospects

- information about the job the jobseeker is looking for: preferred working time, industry and whether he has experience in that industry in the assessment of the caseworker

- the recent labor market history of the unemployed person will be an important signal to the caseworker; it is possible to observe the duration of the unemployment, the level of unemployment benefits or assistance, the industry, wage and the duration of his last job, and if the individual was laid off by his employer, chose to quit or had a fixed term contract. 
But the caseworker's decision will also depend on his perception of the social competence and the motivation of the unemployed individual. These important "soft factors" cannot be observed directly. Still, they will be correlated with the observed variables listed above. Most of what is left should largely be reflected in the employment history of the unemployed person. The employment history was shown to be very important for the identification of the causal effect by matching (Heckman et al., 1998). In the data set, there is daily information on the status of the individual over the last five years. Possible statuses are employment, unemployment, participation in labor market programs (training and job creation schemes) and out of the labor force. As the sample is large, this information can be used in a very detailed way.

There should be enough information on the unemployed to be able to approximate all the criteria which influence both the participation and the outcome in case of not being assigned. Note that more detailed information is available in the data than in other evaluation studies that apply matching, e.g. Dorsett (2005) and Heckman and Smith (2004). So the CIA is plausible and the average effect of treatment on the treated can be estimated by matching. Random variation in the treatment conditional on $\mathrm{X}$, which is needed to achieve common support, will result from the differing motives of the caseworkers discussed above insofar as they are not related to the outcome for the unemployed individual.

\subsection{Implementation of the matching approach}

Some of the covariates as well as the outcome variable are measured with respect to the date on which assignment takes place. For example, the duration of unemployment before assignment is an important covariate; the outcome regular employment is measured 9 months after the assignment date. However, for the individuals who are not assigned, such a starting date does not exist. One possible way around this would be to use one starting date for all the non-participants, for example in the middle of the time span analyzed. But that would lead to a methodological problem. If all the non-participants had the same starting date while the participants had different starting dates, the variables based on these dates would not be independent of the participation.

The problem is accounted for using a method proposed by Lechner (1999) to account for. The starting dates for the non-participants are drawn at random from the distribution of starting dates of the participants. This generates a distribution of starting dates for the nonparticipants which converges to the distribution for the participants. If such a hypothetical 
starting date does not fit with the institutional framework, i.e. if the non-participant is not unemployed at that date, the observation is deleted. ${ }^{14}$ Furthermore, in the propensity score matching the restriction is imposed that only individuals with starting date in the same month can be matched. This additional restriction makes the method similar to that of Sianesi (2004). The latter, however, requires more time-consuming computations.

\section{Empirical estimates}

\subsection{Propensity Score Estimation}

As discussed in Section 5, matching is carried out on the basis of the propensity score. The propensity score is estimated by maximizing a likelihood function based on a standard probit equation, where - according to the CIA - those variables which should influence both the probability of treatment and the outcome in the non-treated state are included. Six sets of variables can be distinguished: socio-demographic attributes, qualifications, information about the last contact with the labor market, information about the preferred new job, recent labor market history and regional indicators. The exact specification was chosen such that the variables are balanced well enough (see Section 6.2). Table A1 in the appendix reports the estimation results including the more important covariates. The omitted results are available upon request or can be found in Kruppe (2006).

It was already apparent from the descriptive statistics that age is an important determinant for the assignments. Age enters the probit estimation as a spline function, so that each variable (e.g. “Age 30 - 35”) represents the influence of age in the respective interval. The results show that the probability of assignment is by far highest for the youngest individuals. It drops sharply approaching age 30, is more or less constant between 30 and 50 years and shows another strong decrease at more than 55 years.

Foreigners have a significantly lower probability of being assigned to a private provider. Women living alone have a higher probability of being assigned than single men. Looking at the interaction effects of female and marital statuses, it becomes evident that the opposite is true for married women and, in eastern Germany, for women living in a partnership without

14 This procedure should not be problematic because the time window is only 3 months for the first sample. For the larger sample, the random starting dates are drawn separately for each quarter, i.e. for all the nonparticipants unemployed in the second quarter, a random starting date from the individuals assigned in the second quarter is drawn. A non-participant unemployed in both quarters can be used as a control two times. 
being married. When it comes to professional training, individuals with classroom vocational training are assigned most often, both for people with and without experience in the desired job. Finally, caseworkers are more likely to assign unemployed individuals who receive a higher daily amount of benefits or assistance. Overall, these results show that the first of the possible motives for the caseworker's decision (Section 5.2) is most important: they tend to assign those individuals for whom a placement seems feasible.

\subsection{Quality of the matching}

The objective of the matching is to balance the covariates that influence both the assignment probability and the outcome in case of no assignment. The degree to which this objective is achieved can be tested by balancing tests. A test commonly used is the standardized difference introduced by Rosenbaum and Rubin (1985). It is calculated for each covariate before and after matching as follows:

$$
\operatorname{SDIFF}_{\text {before }}=100 \frac{\bar{X}_{1}-\bar{X}_{0}}{\sqrt{\left(V_{1}\left(X_{1}\right)+V_{0}\left(X_{0}\right)\right) / 2}} ; \quad \operatorname{SDIFF}_{\text {after }}=100 \frac{\bar{X}_{1 M}-\bar{X}_{0 M}}{\sqrt{\left(V_{1}\left(X_{1}\right)+V_{0}\left(X_{0}\right)\right) / 2}},
$$

where $\bar{X}_{1}$ and $\bar{X}_{0}$ are the means of the covariate in the samples for participants and nonparticipants before matching, $\bar{X}_{1 M}$ and $\bar{X}_{0 M}$ the means in the matched samples and $V_{1}\left(X_{1}\right)$ and $V_{0}\left(X_{0}\right)$ the variances in the unmatched samples. There is not a critical value for the standardized difference, but Rosenbaum and Rubin (1983) call a value of 20 "large”.

Table 3 shows the standardized differences before and after matching for important covariates as well as the maximum of the standardized differences and the share of them which are bigger than 5 . For both regions there is only one variable which has a standardized difference after matching of above 20. These are the dummies for labor market districts where the number of assignments is very small. For about 90 percent of the variables the standardized difference is smaller than 5 . The results show that a good balancing of the covariates was achieved in comparison to other studies. 
Table 3: Balancing test: standardized differences before and after matching for selected covariates, summary statistics

\begin{tabular}{|c|c|c|c|c|}
\hline & \multicolumn{2}{|c|}{ West } & \multicolumn{2}{|c|}{ East } \\
\hline & $\begin{array}{l}\text { Before } \\
\text { matching }\end{array}$ & $\begin{array}{c}\text { After } \\
\text { matching }\end{array}$ & $\begin{array}{l}\text { Before } \\
\text { matching }\end{array}$ & $\begin{array}{l}\text { After } \\
\text { matching }\end{array}$ \\
\hline \multicolumn{5}{|l|}{ general socio-demographic attributes } \\
\hline age (years) & 54.5 & 6.41 & 64.35 & 3.53 \\
\hline foreign & 5.30 & 0.32 & 8.82 & 2.41 \\
\hline female & 1.57 & 0.00 & 11.84 & 0.00 \\
\hline married & 25.12 & 1.60 & 35.14 & 1.63 \\
\hline \multicolumn{5}{|l|}{ schooling } \\
\hline $\mathrm{CSE}$ & 6.74 & 0.75 & 0.89 & $\overline{5.62}$ \\
\hline O-levels & 15.40 & 2.30 & 4.85 & 4.56 \\
\hline adv. Technical college entrance & 5.75 & 5.60 & 0.35 & 1.70 \\
\hline A-levels & 4.62 & 6.18 & 4.36 & 5.32 \\
\hline \multicolumn{5}{|l|}{ vocational training } \\
\hline on-the-job vocational training & 11.64 & 1.53 & 7.06 & 1.77 \\
\hline classroom vocational training & 8.89 & 0.70 & 28.23 & 1.81 \\
\hline technical college & 0.04 & 3.08 & 6.43 & 4.24 \\
\hline university & 8.53 & 3.44 & 5.57 & 4.68 \\
\hline polytechnic & 3.62 & 3.65 & 4.02 & 3.69 \\
\hline \multicolumn{5}{|c|}{ information about working history (short time) } \\
\hline $\begin{array}{l}\text { existing professional experience in } \\
\text { desired occupation }\end{array}$ & 16.53 & 4.01 & 30.43 & 4.88 \\
\hline $\begin{array}{l}\text { duration of unemployment until issue } \\
\text { (days) }\end{array}$ & 28.90 & 0.72 & 30.89 & 0.51 \\
\hline \multicolumn{5}{|l|}{ summary statistics for all covariates } \\
\hline maximum of standardized differences & & 25.01175 & & 21.22293 \\
\hline share of standardized differences > 5 & & $10.80 \%$ & & $9.85 \%$ \\
\hline
\end{tabular}

Source: own calculations using data from the Federal Employment Office, see text

\subsection{Individual effects of contracting out}

The outcome variables are the labor market states regular employment, subsidized employment and unemployment. Figure 3 presents the share of the assigned individuals and of the control groups that were in regular employment 12 months before and 9 months after the treatment date. Whereas the employment shares before the treatment are balanced by the propensity score matching, the employment share for the unemployed individuals assigned to a private provider is smaller than that of the control group in the months after the treatment. The difference between the two shares can be interpreted as the estimated direct treatment effect (ATT) of the assignments. The estimated standard errors presented in Table A2 of the Appendix show that the effects are significant for some months after the treatment. 
Figure 3: Average effect of assignment (complete placements activities) on the assigned individuals (assignments in the first quarter of 2004)
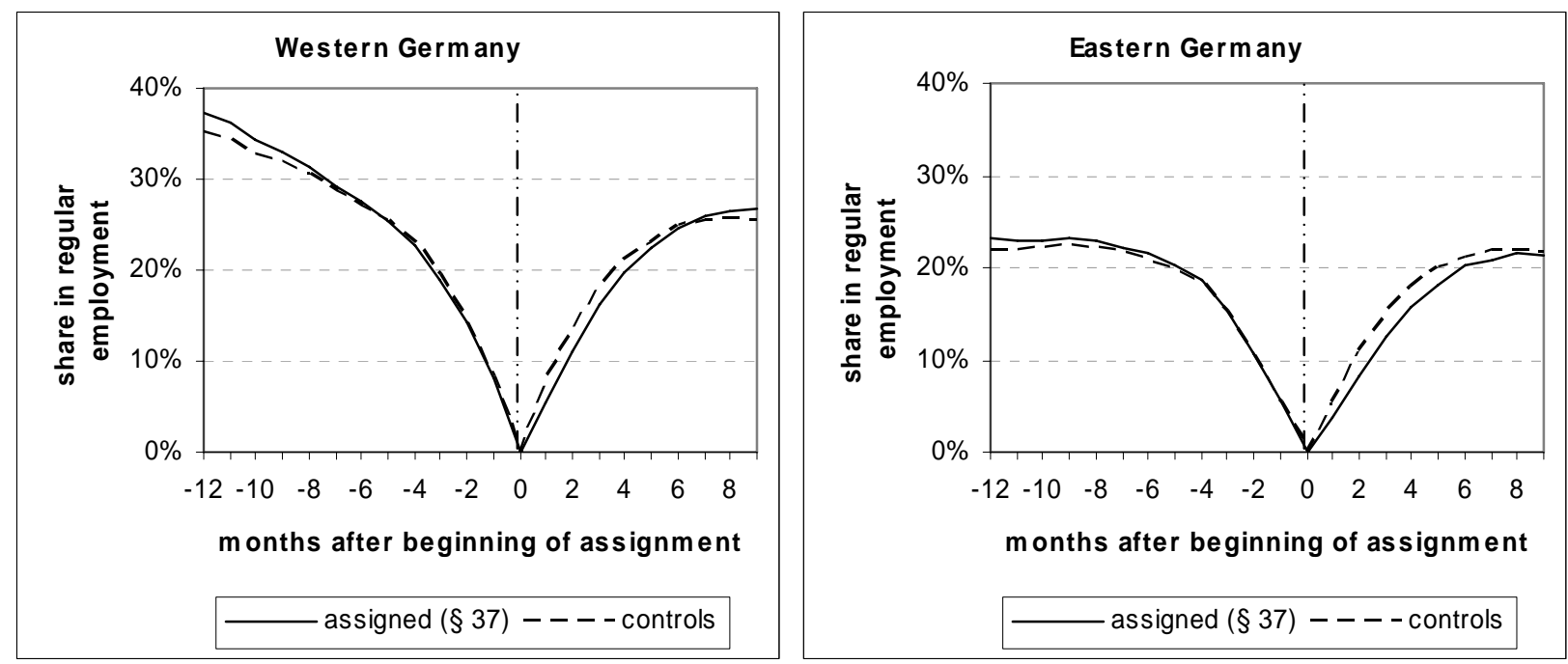

Source: own calculations using data from the Federal Employment Office, see text

So the ATT of the assignments is negative in eastern and western Germany. It is largest after two months (2.6 and 2.3 percentage points) and then diminishes. The results are in line with the usual assignment period of three months. Apparently the private providers were on average less successful than the public employment offices in placing unemployed individuals.

The results for the other two labor market states is shown in Table A2 in the appendix. The effect on unemployment is even stronger than that on regular employment: up to 7.1 percentage points after 3 months in eastern Germany (western Germany: 5.9). But this effect also starts to vanish after the assignment period. ${ }^{15}$ The conclusion is that the assignments of unemployed individuals to private providers in the first quarter of 2004 had on average negative short-term effects on these individuals and no long-term effects. These results are confirmed by an analysis for a broader sample including the assignments in the first half of 2004 (Winterhager, 2006). The ineffectiveness of the contracting out scheme can be explained by the deficits in the contract management identified as a result of the theoretical considerations in Section 2. The design of the tender allowed providers who combined low

15 Calculating the residual of the three labor market states observed here shows that there must be a small negative effect on the residual states. These are participation in training programs, out of the labor force and self employment. 
quality with a low price to be awarded the contracts. Information mechanisms did not seem to be effective and the incentive effect of the premiums was rather small.

The results presented so far are averages for all the unemployed individuals assigned to a private contractor. It is of interest here whether these effects are the same for different sociodemographic groups or if there are particularities. Figures A1 and A2 in the appendix present the effects on regular employment for genders and three age groups separately. In western Germany, the effects are better for women: the effect becomes positive after 5 months. Regarding age, the assignments appear to be somewhat more advantageous (or less disadvantageous) for unemployed persons older than 50 years.

\subsection{Estimated effects and the design of the tender}

As discussed in Section 2, there are different compensation schemes for the private providers. Whereas contracts signed before 2004 were not subject to a standardized compensation scheme, there were three types of compensation depending on the previous duration of unemployment for contracts in 2004: performance based payment only (less than 6 months of unemployment), performance based payment plus a 15 percent lump sum (6 to 12 months) and performance based payment plus a 25 percent lump sum (more than a year). The actual amount of the compensation depends on the result of the tender.

Possible connections between compensation amount and treatment effect have been discussed in the theoretical part of Section 2. It was argued that a higher performance based payment should lead to increased efforts on the part of the private provider and thus to a bigger treatment effect. The empirical relationship is presented in Figures 4 and 5 . This analysis is presented for the larger sample with assignments from January to June 2004 to have more variation in the amount of the premium. The figures show the treatment effects for assignments into the three standardized and the non-standardized contracts. For each contract type (including the non-standardized contracts of 2003) the effects are differentiated according to the amount of the payment in case of successful placement: less than 200 Euro, between 200 and 400 Euro and more than 400 Euro. Even though the picture is not completely unambiguous, there seems to be a positive correlation between amount of the premium and treatment effect. The effects of the assignments after six months with premium of more than 400 Euro rank highest in five cases and lowest in only one case. 
Figure 4: Average effect of assignments (complete placements activities) for the assigned individuals in different types of assignments with different amounts of premium (assignments in the first half of 2004 in western Germany), number of cases in brackets in the legend
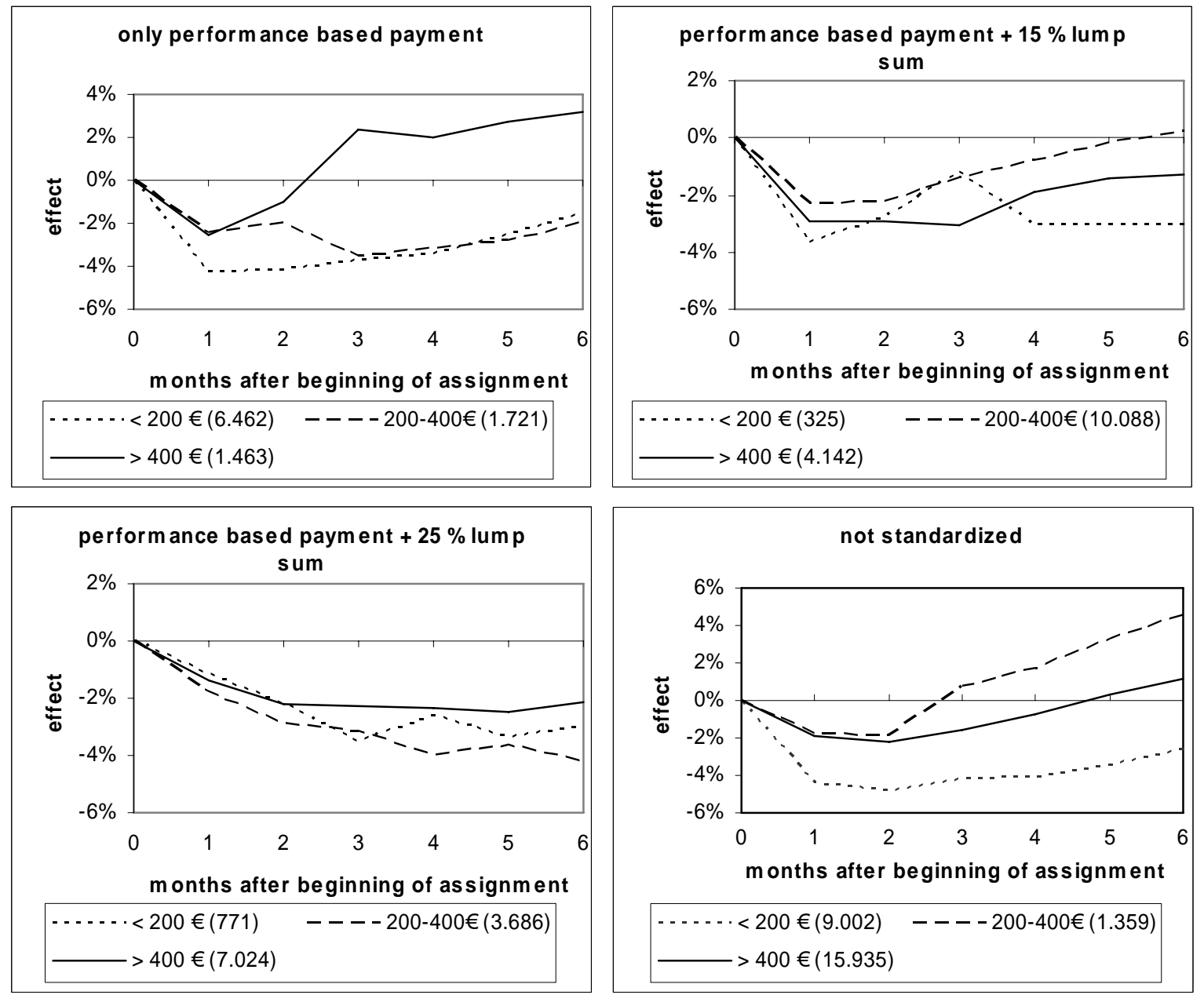

Source: own calculations using data from the Federal Employment Office, see text

This correlation between the amount of the premium and the estimated treatment effect does not have a causal interpretation. To establish such a relationship, one would first have to control for individual and regional characteristics which imply different treatment effects as shown in the last section. This is done here by an OLS regression of the "individual treatment effect” (i.e. for each treated individual, the difference in the outcome variable between his own outcome and the outcome for his control person) on all the characteristics also used in the propensity score estimation plus the amount of the premium contracted for this individual. Table 4 shows that for eastern Germany the positive coefficient is significant. 
Figure 5: Average effect of assignments (complete placements activities) for the assigned individuals in different types of assignments with different amounts of premium (assignments in the first half of 2004 in eastern Germany), number of cases in brackets in the legend
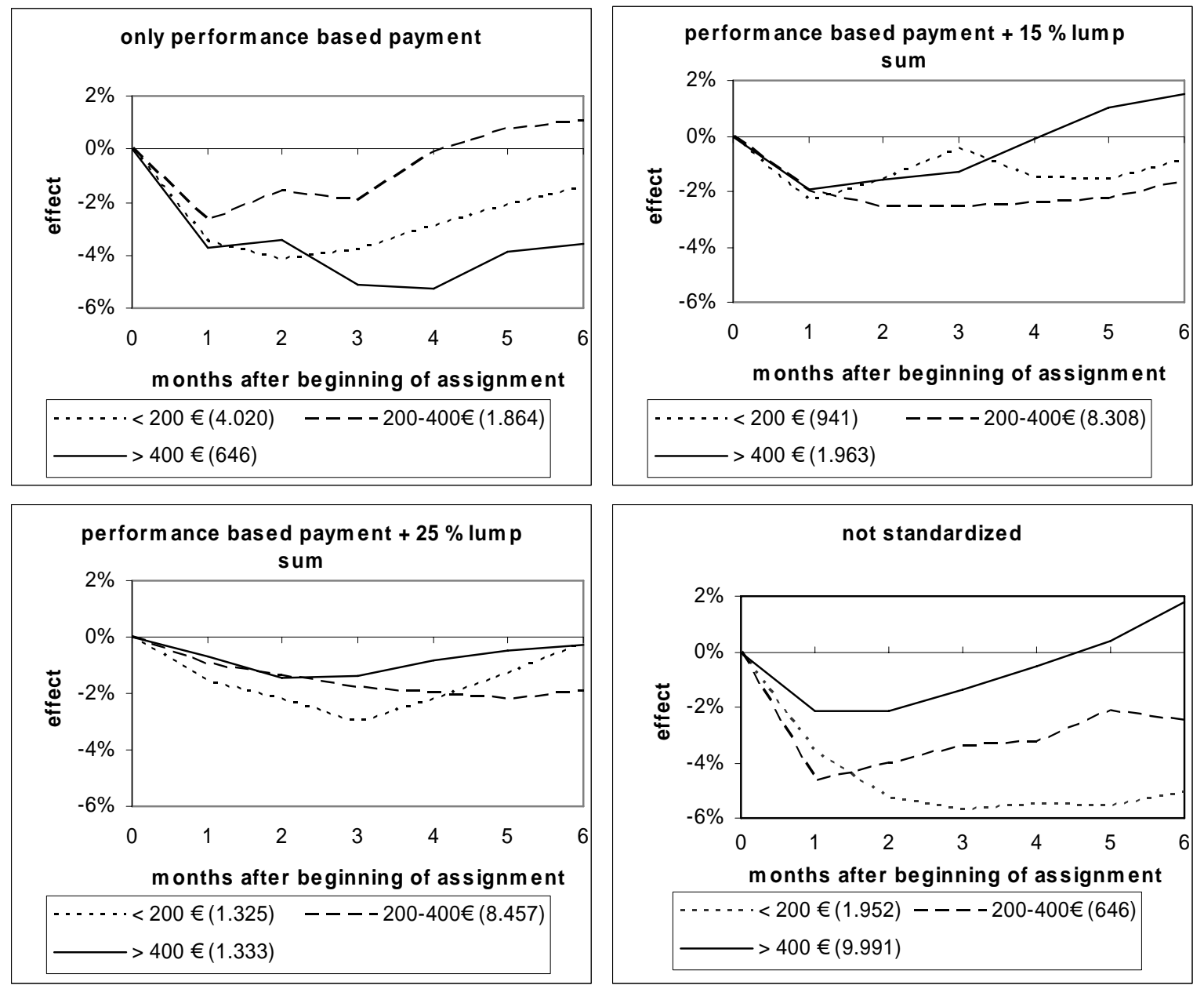

Source: own calculations using data from the Federal Employment Office, see text

However, this regression poses the problem that the premium is endogenously determined in the tender, so the coefficient is biased. If for unemployed persons with lower expected treatment effects higher premiums are contracted, the coefficient is biased downward. To control for this one would need an instrumental variable which is partially correlated to the amount of the premium but not directly correlated to the estimated treatment effect. One might think of using data about the tender, like the number of offers submitted in the labor market district relative to the number of contracts, which would indicate the market tightness. Unfortunately, such data are not available for the introductory period in 2004, although they might be for later tenders.

Altogether, it does not seem to be possible to establish a causal relationship between the amount of the premium and the estimated treatment effect for 2004. It might be possible in 
the future and would certainly be very useful, because the premium is an important parameter of the instrument.

Table 4: Regression of the "individual" treatment effect on the individual characteristics and the amount of the premium; coefficients of the amount of the premium

\begin{tabular}{lrcc}
\hline \hline $\begin{array}{l}\text { West } \\
\text { amount of the premium }\end{array}$ & coefficient & standard error & t-value \\
\hline $\begin{array}{l}\text { Ost } \\
\text { amount of the premium }\end{array}$ & $0,0011 \%$ & $0,0009 \%$ & 1,18 \\
\hline \hline
\end{tabular}

Source: own calculations using data from the Federal Employment Office, see text

\section{Conclusions}

Contracting out might be a tool to make placement services for unemployed individuals more effective and efficient and thereby reduce frictional unemployment. It is regulated by $\S$ 37 SGB III in Germany, which was introduced in 2002. Contracts were standardized at the beginning of 2004. After going into some theoretical considerations based on new institutional economics, this paper analyzes the use of this instrument and its effectiveness from the perspective of the unemployed individuals assigned to a private provider for the complete placement activities. It also takes a closer look at the connection between the compensation and the estimated treatment effects.

Contracting out was not widely used in 2004. Only 8 percent of the people who registered as unemployed from January to September 2004, or 250.000 jobseekers, were assigned to a private provider for complete placement activities during that time. The total costs of the assignments for complete placement activities were less than 70 million $€$ for 2004 . On average, it tends to be the jobseekers with better employment opportunities who are assigned to the private providers.

Treatment is defined as the first approach to the private provider after the assignment during the first quarter of 2004. The outcomes, regular employment, subsidized employment and unemployment can be observed for nine months up to December 2004. The selectivity of the assignments is taken into account in the microeconometric evaluation study that uses propensity score matching to solve the evaluation problem. The plausibility of the identifying matching assumptions is discussed. It is argued that they hold, i.e. the matched control group is a reliable proxy for the unobserved counterfactual. The CIA should hold 
because the highly informative administrative data provided by the Federal Employment Agency minimizes selection on unobservables. Unobserved heterogeneity is small enough to get a negligible bias. The common support is given because assignment to the providers is not deterministic conditional on observable characteristics, but varies due to differing attitudes towards the instrument.

The estimated effect of the assignments on the probability of employment is small and negative: 2.3 to 2.6 percentage points after 2 months. The positive effects on the probability of unemployment are even bigger, up to 7 percentage points. The effects are only temporary, vanishing after some months. This is in line with the assignment duration of three months. On average, the private providers were less successful in placing their clients than the public employment offices at the beginning of 2004. The theoretical analysis hints at the possible reasons: there were important deficits in the contract management for the contracting out at that time. The design of the tender allowed providers who combined low quality with a low price to be awarded the contracts. Information mechanisms did not seem to be effective and the incentive effect of the premiums was rather small.

The results show a positive relationship between the amount of the premium and the estimated treatment effect, as one would expect from a theoretical perspective: a higher premium implies a larger incentive for the private provider to invest into placement activities. However, establishing a causal relationship is problematic because an instrumental variable for the premium is not available for 2004.

The results of this microeconometric evaluation suggest that there should be modifications in the contracting out of placement services relative to the 2004 design. Given the theoretical considerations and the empirical evidence, the design of the tender and the compensation scheme should be taken as a starting point for these changes. An econometric evaluation of such changes will provide additional insight into the connection between contract management and treatment effects. 


\section{References}

Angrist, J. D. and A. Krueger (1999), Empirical Strategies in Labor Economics, in: Ashenfelter, O. and D. Card (Eds.), The Handbook of Labor Economics, North-Holland, Amsterdam, Vol. 3A: 1277-1366.

Baumol, W. J. (1982), Contestable markets: An uprising in the theory of industry structure, American Economic Review, 72 (1), 1-15.

Blundell, R. and M. Costa Dias (2002), Alternative approaches to evaluation in empirical microeconomics, Portuguese Economic Journal, 1 (2), 91-116.

Bruttel, O. (2005), New Private Delivery Arrangements in Germany: An Initial Evaluation Using New Institutional Economics, in: Sol, E. und M. Westerveld (Eds.), Contractualism in Employment Services, Kluwer, Amsterdam, 209-230.

Buttler, F. and U. Walwei (1995), Different Institutional Arrangements for Job Placement, in: Buttler, F., Franz, W., Schettkat, R. and D. Soskice: Institutional Frameworks and Labor Market Performance, Routledge, London and New York: 248-269.

Dehejia, R.H. and S. Wahba (2002), Propensity Score Matching Methods for Nonexperimental Causal Studies, Review of Economics and Statistics 84 (1), 151-161.

DellaVigna, S. and M.D. Paserman (2005), Job Search and Impatience, Journal of Labor Economics 23(3), 527-588.

Dockery, A. M. and T. Stromback (2001), Devolving public employment services: Preliminary assessment of the Australian experiment, International Labour Review 140 (4), 429-451.

Dorsett, R. (2005), The new deal for young people: effect on the labour market status of young men, Labour Economics (forthcoming).

Furubotn, E. G and R. Richter (1998), Institutions and economic theory: The contribution of the new institutional economics, Ann Arbor, MI, University of Michigan Press.

Gerfin, M. und M. Lechner (2002), Microeconometric Evaluation of the Active Labour Market Policy in Switzerland, The Economic Journal, 112 (482), 854-893.

Hart, O., A. Schleifer and R. Vishny (1997), The Proper Scope of Government: Theory and an Application to Prison, Quaterly Journal of Economics, 112(4), 1127-1161.

Hartz-Kommission (2002), Moderne Dienstleistungen am Arbeitsmarkt. Vorschläge der Kommission zum Abbau der Arbeitslosigkeit und zur Umstrukturierung der Bundesanstalt für Arbeit, Berlin.

Heckman, J. J., H. Ichimura, J. Smith und P. Todd (1998), Characterizing Selection Bias Using Experimental Data, Econometrica 66, 1017-1098.

Heckman, J. J., H. Ichimura and P. Todd (1997), Matching as an Econometric Evaluation Estimator: Evidence from Evaluating a Job Training Programme, Review of Economic Studies 64, 605-654.

Heckman, J. J., R. J. LaLonde and J. A. Smith (1999), The Economics and Econometrics of Active Labour Market Programs, in: Ashenfelter, O. and D. Card (Eds.), Handbook of Labor Economics, North-Holland, Amsterdam, Vol. 3a, 1865-2097.

Heckman, J. and J. Smith (2004), The Determinants of Participation in a Social Program: Evidence from a Prototypical Job Training Program, Journal of Labor Economics, 22 (4), 243-298.

Heidinger, M. (2002), Arbeitsmarktpolitik bei marktkonformer Arbeitsvermittlung: Ein Reformvorschlag aus konstitutionenökonomischer Perspektive, Peter Lang, Frankfurt am Main.

Heinze, A., F. Pfeiffer, A. Spermann, H. Winterhager and A. Wuppermann (2005), Vermittlungsgutscheine, Teil I - Datenstruktur und deskriptive Analysen, IAB-Forschungsbericht $1 / 2005$.

Hujer, R. Caliendo, M. and Thomsen, S. (2004), New Evidence on the Effects of Job Creation Schemes in Germany - A Matching Approach with Threefold Heterogeneity, Research in Economics, 58 (4), 257-302. 
Hummel, E., P. Jacobebbinghaus, A. Kohlmann, M. Oertel, C. Wübbeke und M. Ziegerer (2005): Stichprobe der Integrierten Erwerbsbiografien - IEBS 1.0, Handbuch-Version 1.0.0, FDZ Datenreport Nr. 06.

Kettner, A. and E. Spitznagel (2005), Gesamtwirtschaftliches Stellenangebot gering, IAB-Kurzbericht 6/2005.

Konle-Seidl, R. (2005), New Delivery Forms of Employment Services in Germany: A Mixed PublicPrivate Model?, in: Sol, E. und M. Westerveld (Eds.), Contractualism in Employment Services, Amsterdam University Press, Amsterdam, 187-208.

Konle-Seidl, R. and U. Walwei (2002), Wandel der Arbeitsvermittlung durch Deregulierung: Mehr Reputation durch Marktöffnung?, in Kleinhenz, G.: IAB Kompendium Arbeitsmarkt- und Berufsforschung, Nürnberg, Vol. 250, 171-185.

Kretschmer, A. (2005), Die Organisation der Arbeitsvermittlung: Ökonomische Analyse und Gestaltungsempfehlungen aus der australischen Vermittlungspraxis, Logos, Berlin.

Kruppe, T. (Ed.) (2006), Private Vermittlung als Unterstützung: Eine Evaluation von Vermittlungsgutscheinen und Beauftragungen Dritter, BeitrAB 301, IAB, Nürnberg.

Lechner, M. (1999), Earnings and Employment Effects of Continuous Off-the-Job Training in East Germany After Unification, Journal of Business \& Economic Statistics 17 (1): 74-90.

Lechner , M. (2001), Identification and estimation of causal effects of multiple treatments under the conditional independent assumption, in: Lechner M. and F. Pfeiffer (Eds.), Econometric Evaluation of Labor Market Policies, Physica, Heidelberg, 43-58.

Lechner, M. (2002), Some practical issues in the evaluation of heterogeneous labour market programmes by matching methods, Journal of the Royal Statistical Society Association 165, 5982.

Lechner, M. and F. Pfeiffer (2001), Econometric Evaluation of Labor Market Policies, Physica, Heidelberg, 43-58.

Lechner, M., Pfeiffer, F., Spengler H. and M. Almus (2001), The impact of non-profit temping agencies on individual labor market success, in Lechner, M. and F. Pfeiffer (Eds.), Econometric Evaluation of Labor Market Policies, Heidelberg, 211-242.

Martin, S. (1993), Advanced Industrial Economics, Blackwell, Oxford.

OECD (2003), The Competitive Market for Employment Services in the Netherlands, OECD Social, Employment and Migration Working Paper.

Pfeiffer, F. and H. Winterhager (2006a), Selektivität und direkte Wirkungen von Vermittlungsgutscheinen: Empirische Befunde aus der Einführungsphase, Perspektiven der Wirtschaftspolitik 7 (3) (in press).

Pfeiffer, F. and H. Winterhager (2006b), Kosten-Nutzen-Abschätzungen zu den Beauftragungen mit der gesamten Vermittlung nach $\S 37$ SGB III, in Kruppe, T. (Ed.): Private Vermittlung als Unterstützung: Eine Evaluation von Vermittlungsgutscheinen und Beauftragungen Dritter Beiträge zur Arbeitsmarkt- und Berufsforschung, Nürnberg.

Rosenbaum, P.R. and D.B. Rubin (1983), The Central role of the Propensity Score in Observational Studies for Causal Effects, Biometrika 70 (1), 1-55.

Rosenbaum, P.R. und D.B. Rubin (1985), Constructing a Control Group Using Multivariate Matched Sampling Methods That Incorporate the Propensity Score, The American Statistician, Feb. 1985, Vol. 39, No. 1.

Rubin, D. (1980), Comment of Badu, D. - Randomization Analysis of Experimental Data: The FisherRandomization Test, Journal of the American Statistical Association, 75, 591-593.

Sianesi, B. (2004), An Evaluation of the Swedish System of Active Labor Market Programs in the 1990s, Review of Economics and Statistics 86 (1), 133-155.

Struyven, L. and G. Steurs (2004), Two countries, one system?, mimeo. 
sinus (2006), Implementationsanalyse, in Kruppe, T. (Ed.): Private Vermittlung als Unterstützung: Eine Evaluation von Vermittlungsgutscheinen und Beauftragungen Dritter, BeitrAB 301, IAB, Nürnberg.

Williamson, O. E. (1985), The economic institutions of capitalism, New York, Free Press.

Winterhager, H. (2006), Mikroökonometrische Analyse der direkten Effekte von Beauftragungen mit der gesamten Vermittlung, in Kruppe, T. (Ed.): Private Vermittlung als Unterstützung: Eine Evaluation von Vermittlungsgutscheinen und Beauftragungen Dritter, BeitrAB 301, IAB, Nürnberg.

Winterhager, H., A. Heinze and A. Spermann (2006), Deregulating Job Placement in Europe: A Microeconometric Evaluation of an Innovative Voucher Scheme in Germany, Labour Economics, forthcoming. 


\section{Appendix}

Figure A1: Average effect of assignments (complete placements activities) for the assigned individuals by gender (assignments in the first quarter of 2004)
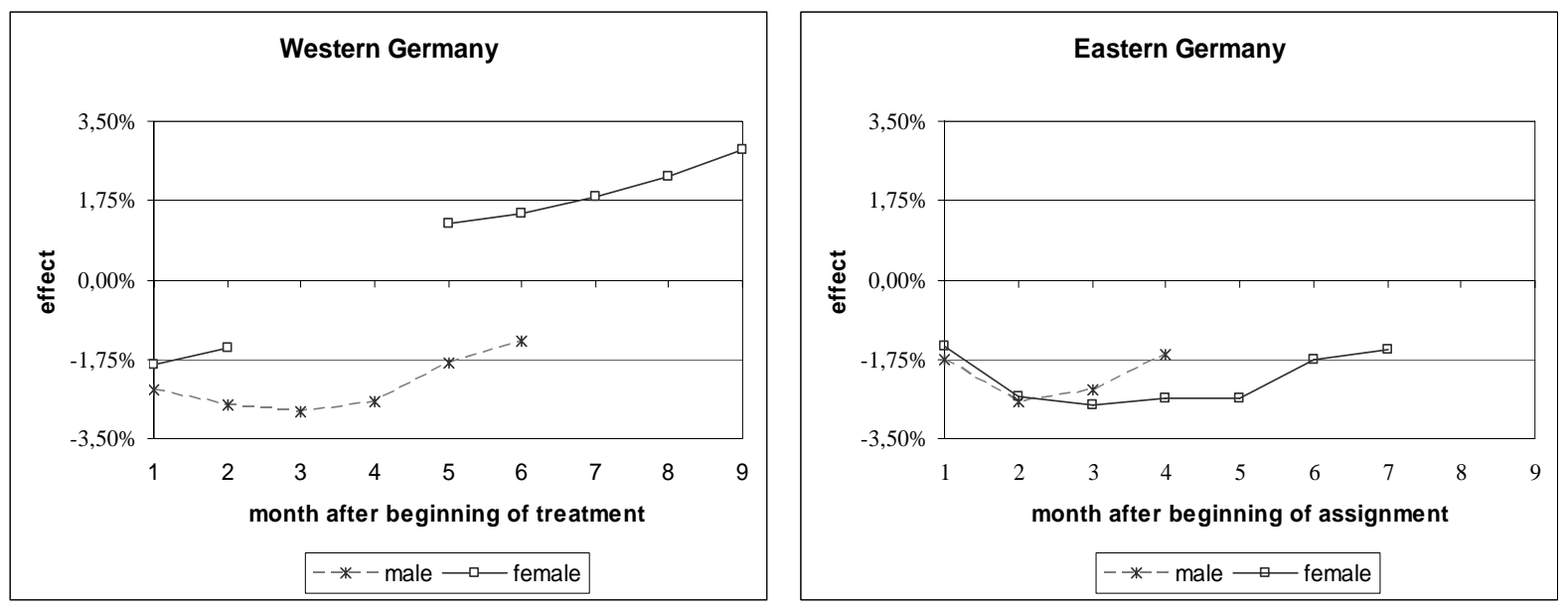

Source: own calculations using data from the Federal Employment Office, see text

Figure A2: Average effect of assignments (complete placements activities) for the assigned individuals by age group (assignments in the first quarter of 2004)

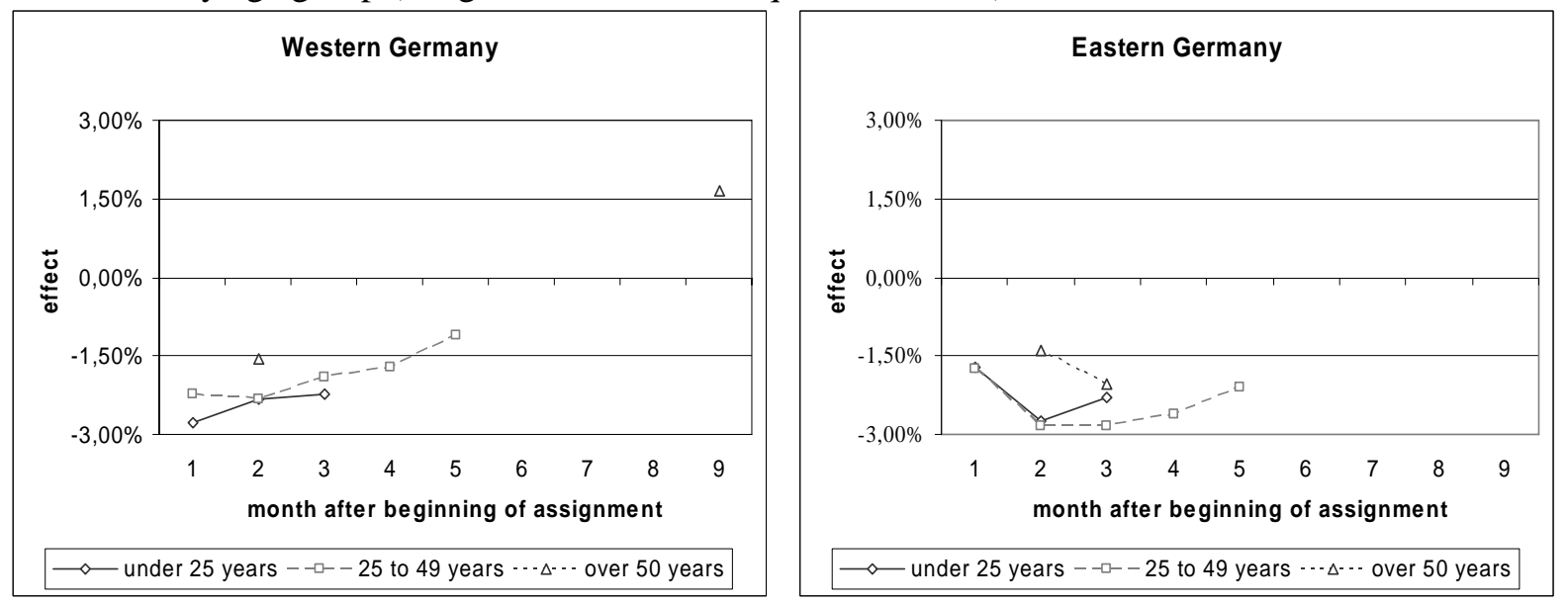

Source: own calculations using data from the Federal Employment Office, see text 
Table A1: Probit estimation of the Propensity Score, number of covariates incomplete

\begin{tabular}{|c|c|c|c|c|}
\hline & \multicolumn{2}{|l|}{ West } & \multicolumn{2}{|l|}{ East } \\
\hline Pseudo R-squared & \multicolumn{2}{|l|}{0.1591} & \multicolumn{2}{|l|}{0.1558} \\
\hline Variable & $\begin{array}{c}\text { Coefficient } \\
\text { (marginal } \\
\text { effect) }\end{array}$ & $\mathrm{z}$ & $\begin{array}{c}\text { Coefficient } \\
\text { (marginal } \\
\text { effect) }\end{array}$ & $\mathrm{z}$ \\
\hline \multicolumn{5}{|c|}{ General socio-demographic attributes } \\
\hline Age (Spline function) & & & & \\
\hline Age 0 & -0.00075 & -21.72 & -0.00166 & -19.59 \\
\hline Age 25 & -0.00067 & -18.94 & -0.00133 & -15.93 \\
\hline Age 30 & 0.00013 & 3.68 & 0.00029 & 3.42 \\
\hline Age 35 & -0.00002 & -0.64 & -0.00021 & -2.79 \\
\hline Age 40 & 0.00001 & 0.34 & -0.00019 & -2.64 \\
\hline Age 45 & -0.00008 & -2.06 & -0.00023 & -3.00 \\
\hline Age 50 & -0.00046 & -10.12 & -0.00056 & -6.10 \\
\hline Age 55 & -0.00198 & -16.07 & -0.00273 & -11.54 \\
\hline Age 60 & 0.00095 & 2.89 & 0.00055 & 0.56 \\
\hline Foreign & -0.00028 & -2.99 & -0.00275 & -4.31 \\
\hline Female & \begin{tabular}{|r|}
0.00042 \\
\end{tabular} & 3.92 & 0.00106 & 3.96 \\
\hline Single & \multicolumn{4}{|l|}{ reference } \\
\hline Partnership, not married & 0.00004 & 0.20 & 0.00038 & 1.16 \\
\hline Single parent & 0.00076 & 1.75 & -0.00087 & -1.04 \\
\hline Married & 0.00022 & 2.08 & 0.00012 & 0.48 \\
\hline $\begin{array}{l}\text { Female * (partnership, not } \\
\text { married) }\end{array}$ & -0.00015 & -0.50 & -0.00169 & -3.74 \\
\hline Female * (single parent) & -0.00043 & -1.05 & -0.00008 & -0.08 \\
\hline Female $*$ (married) & -0.00078 & -5.52 & -0.00147 & -4.67 \\
\hline Children 0-3 years (dummy) & -0.00002 & -0.14 & -0.00103 & -3.16 \\
\hline Children 3-7 years (dummy) & 0.00001 & 0.06 & -0.00053 & -1.70 \\
\hline Children 7-14 years (dummy) & 0.00008 & 0.61 & -0.00045 & -1.70 \\
\hline \multicolumn{5}{|l|}{ Qualification } \\
\hline No professional training & reference & & & \\
\hline on-the-job vocational training & 0.00018 & 1.03 & 0.00220 & 5.93 \\
\hline classroom vocational training & 0.00230 & 5.84 & 0.00488 & 8.54 \\
\hline technical college & 0.00038 & 1.01 & 0.00442 & 3.85 \\
\hline university & -0.00144 & -3.19 & -0.00198 & -1.37 \\
\hline polytechnic & -0.00139 & -2.42 & -0.00068 & -0.41 \\
\hline $\begin{array}{l}\text { experience in preferred job } \\
\text { according to the assessment of } \\
\text { caseworker (dummy) }\end{array}$ & -0.00031 & -2.10 & 0.00073 & 1.85 \\
\hline
\end{tabular}


Table A1, continued

Interaction of experience and professional training:

Exp. * on-the-job vocational training

Exp. ${ }^{*}$ classroom vocational training

Exp. * technical college

Exp. * university

0.00065

$-0.00037$

$-0.00012$

0.00183

0.00215
$-2.81$

$-2.52$

$-3.09$

2.12

0.79

Exp.* polytechnic

\begin{tabular}{l|r|r|r|r}
\hline unskilled employee & reference & & \\
skilled employee & 0.00029 & 3.06 & 0.00042 & 2.39 \\
Technical school level & 0.00062 & 2.57 & 0.00024 & 0.41 \\
Polytechnic level & -0.00079 & -2.53 & 0.00150 & 1.76 \\
top executive or university level & -0.00135 & -4.62 & 0.00229 & 2.47 \\
others & 0.00028 & 0.80 & 0.00310 & 3.61 \\
\hline Change of industry & -0.00024 & -3.62 & 0.00040 & 2.38 \\
\hline
\end{tabular}

Last contact with labor market

Daily wage in last employment (€):

\begin{tabular}{|c|c|c|c|c|}
\hline no previous wage & reference & & & \\
\hline above 0 , up to 20 & -0.00011 & -0.80 & 0.00058 & 1.97 \\
\hline above 20 , up to 40 & 0.00011 & 1.04 & 0.00060 & 3.26 \\
\hline above 40 , up to 60 & 0.00015 & 1.51 & -0.00012 & -0.61 \\
\hline above 60 , up to 80 & -0.00011 & -0.96 & 0.00022 & 0.59 \\
\hline above 80 , up to 100 & -0.00025 & -1.50 & 0.00094 & 1.36 \\
\hline above 100 & -0.00052 & -2.73 & -0.00094 & -1.10 \\
\hline \multicolumn{5}{|c|}{ Reason for end of previous employment } \\
\hline dismissal & 0.00011 & 1.15 & -0.00041 & -1.66 \\
\hline Fixed-term contract & 0.00038 & 3.34 & 0.00004 & 0.15 \\
\hline Other reason & reference & & & \\
\hline
\end{tabular}

Daily amount of unemployment benefits / assistance $(€)$

no benefit / assistance

above 0 , up to 10

above 10 , up to 15

above 15 , up to 20

above 20, up to 25

above 25 , up to 30

above 30 , up to 40

above 40

reference

The following covariates are not included in the table: dummies for disabilities and health problems (5),

secondary school qualifications (4), favored occupational field (20), preferred working time (4), long term labor market history (96), labor market districts (34 for eastern and 146 for western Germany), spline function for duration of previous unemployment (25).

Source: own calculations using data from the Federal Employment Office, see text 
Table A2: ATT with standard errors in the 9 months after the assignment date (assignments from January to March 2004), labor market states: regular employment, subsidized employment and unemployment

\begin{tabular}{|c|c|c|c|c|c|c|}
\hline \multirow[b]{3}{*}{ month after treatment } & \multicolumn{4}{|c|}{ Western Germany } & \multirow{2}{*}{\multicolumn{2}{|c|}{ unemployment }} \\
\hline & \multicolumn{2}{|c|}{ regular employment } & \multicolumn{2}{|c|}{ subsidized employment } & & \\
\hline & ATT & $\begin{array}{c}\text { standard } \\
\text { error }\end{array}$ & ATT & $\begin{array}{c}\text { standard } \\
\text { error }\end{array}$ & \multicolumn{2}{|r|}{$\begin{array}{c}\text { standard } \\
\text { error }\end{array}$} \\
\hline 1 & $-2.20 \%$ & $0.21 \%$ & $-0.73 \%$ & $0.10 \%$ & $4.78 \%$ & $0.29 \%$ \\
\hline 2 & $-2.25 \%$ & $0.29 \%$ & $-0.65 \%$ & $0.13 \%$ & $5.65 \%$ & $0.37 \%$ \\
\hline 3 & $-1.93 \%$ & $0.33 \%$ & $-0.59 \%$ & $0.16 \%$ & $5.94 \%$ & $0.41 \%$ \\
\hline 4 & $-1.43 \%$ & $0.35 \%$ & $-0.28 \%$ & $0.18 \%$ & $5.11 \%$ & $0.43 \%$ \\
\hline 5 & $-0.61 \%$ & $0.36 \%$ & $-0.13 \%$ & $0.19 \%$ & $4.03 \%$ & $0.44 \%$ \\
\hline 6 & $-0.25 \%$ & $0.37 \%$ & $-0.10 \%$ & $0.20 \%$ & $2.98 \%$ & $0.45 \%$ \\
\hline 7 & $0.42 \%$ & $0.38 \%$ & $-0.41 \%$ & $0.20 \%$ & $2.36 \%$ & $0.45 \%$ \\
\hline 8 & $0.75 \%$ & $0.38 \%$ & $0.37 \%$ & $0.20 \%$ & $1.47 \%$ & $0.45 \%$ \\
\hline 9 & $1.28 \%$ & $0.38 \%$ & $0.48 \%$ & $0.20 \%$ & $0.66 \%$ & $0.44 \%$ \\
\hline \multicolumn{7}{|c|}{ Eastern Germany } \\
\hline & \multicolumn{2}{|c|}{ regular employment } & \multicolumn{2}{|c|}{ subsidized employment } & \multicolumn{2}{|c|}{ unemployment } \\
\hline month after treatment & ATT & $\begin{array}{c}\text { standard } \\
\text { error }\end{array}$ & ATT & $\begin{array}{c}\text { standard } \\
\text { error }\end{array}$ & ATT & $\begin{array}{c}\text { standard } \\
\text { error }\end{array}$ \\
\hline 1 & $-1.63 \%$ & $0.24 \%$ & $-1.34 \%$ & $0.17 \%$ & $4.56 \%$ & $0.35 \%$ \\
\hline 2 & $-2.64 \%$ & $0.34 \%$ & $-1.54 \%$ & $0.21 \%$ & $6.52 \%$ & $0.46 \%$ \\
\hline 3 & $-2.56 \%$ & $0.39 \%$ & $-1.43 \%$ & $0.24 \%$ & $7.11 \%$ & $0.52 \%$ \\
\hline 4 & $-2.05 \%$ & $0.42 \%$ & $-1.39 \%$ & $0.27 \%$ & $6.50 \%$ & $0.55 \%$ \\
\hline 5 & $-1.81 \%$ & $0.44 \%$ & $-1.27 \%$ & $0.29 \%$ & $5.89 \%$ & $0.56 \%$ \\
\hline 6 & $-0.97 \%$ & $0.46 \%$ & $-1.05 \%$ & $0.30 \%$ & $4.91 \%$ & $0.57 \%$ \\
\hline 7 & $-1.01 \%$ & $0.47 \%$ & $-0.16 \%$ & $0.31 \%$ & $3.75 \%$ & $0.58 \%$ \\
\hline 8 & $-0.48 \%$ & $0.47 \%$ & $0.21 \%$ & $0.31 \%$ & $2.67 \%$ & $0.59 \%$ \\
\hline 9 & $-0.30 \%$ & $0.46 \%$ & $0.63 \%$ & $0.30 \%$ & $1.46 \%$ & $0.59 \%$ \\
\hline
\end{tabular}

Source: own calculations using data from the Federal Employment Office, see text 